\title{
Erratum to: Impact of energy loss index on left ventricular mass regression after aortic valve replacement
}

\author{
Terumasa Koyama • Hiroyuki Okura - Teruyoshi Kume $\cdot$ Kenzo Fukuhara • \\ Koichiro Imai • Akihiro Hayashida • Yoji Neishi - Takahiro Kawamoto • \\ Kazuo Tanemoto $\cdot$ Kiyoshi Yoshida
}

Published online: 1 March 2014

(C) Japanese Society of Echocardiography 2014

\section{Erratum to: J Echocardiogr}

DOI 10.1007/s12574-013-0196-7

The original version of this article unfortunately contained errors.

In the Methods section under the subheading "Echocardiography," in the first paragraph, the 13th sentence, "The ELCo was calculated as [EOA - AA]/(AA - EOA) $[12,13,18] . "$ should be "The ELCo was calculated as $[\mathrm{EOA} \times \mathrm{AA}] /(\mathrm{AA}-\mathrm{EOA})[12,13,18] . "$

In the Discussion section, in the fourth paragraph, the last sentence, "Theoretically, ELI the reflects LV pressure overload better than the EOAI." should be "Theoretically, the ELI reflects LV pressure overload better than the EOAI."

In Table 4, "Atrial fibrillation (\%)" should be "Atrial fibrillation $[n(\%)]$."

The authors apologize for the errors.

The online version of the original article can be found under doi: 10.1007/s12574-013-0196-7.

T. Koyama ( $\varangle) \cdot$ H. Okura · T. Kume · K. Fukuhara · K. Imai ·

A. Hayashida $\cdot$ Y. Neishi - T. Kawamoto $\cdot$ K. Yoshida

Division of Cardiology, Kawasaki Medical School,

577 Matsushima, Kurashiki 701-0192, Japan

e-mail: terumasa.k@med.kawasaki-m.ac.jp;

terumasa.k7965@gmail.com

K. Tanemoto

Division of Cardiovascular Surgery, Kawasaki Medical School,

Kurashiki, Japan 